\title{
CONSTRUCTION OF PROGRAMMING EDUCATION ENVIRONMENT USING PROBLEM SOLVING ENVIRONMENT
}

\author{
SHINJI HIOKI \\ Tezukayama University \\ 631-8501 Tezukayama7-1-1, Nara, Japan \\ hioki@tezukayama-u.ac.jp
}

Key words: e-learning, Programming, Self-learning, Problem Solving Environment.

\begin{abstract}
There are many problems in the research and educational field. Japanese PSE has started in the research area: DEQSOL and NCAS. In Japanese elementary school, programming education will begin this year. After that, the programming education in junior high school and high school are also planned. Thus, the need for programming education is highly expected recently. However, it seems not satisfactory when it comes to self-study environment. In this article, construction of the educational platform (internet sites ) for the programming beginners will be introduced. This sites includes three programming languages to learn: scratch, $\mathrm{C}++$ and python. Users ( learners ) meets the question first, then answer this question in terms of their programming code. Efficiency in the university class is briefly discussed.
\end{abstract}

\section{INTRODUCTION}

At the 13th PSE Workshop in Japan, Prof.Tago gave a lecture entitled "PSE Short Story" [1]. In his article, "PSE research in Japan started with the development of "DEQSOL" by Prof.Umetani. This is a system that generates numerical simulation programs in FORTRAN by inputting partial differential equations (PDEs) used in physical simulations and their numerical solutions in a dedicated description language. In the 1990s, Prof.Kawata developed NCAS, a system that automatically generates $\mathrm{C}$ programs and discretizes PDEs when they are input directly into a computer." This shows that PSE research in Japan was born to solve certain "problems" in various "research fields.

Prof.Tago also said that "There is another area where PSE has attracted attention along with the spread of PCs. There have been many hopes for using PSE in education and human resource development in the future. As PCs became popular in education, many educational tools were developed. In addition, as students began to own PCs, they were able to study at home or in the classroom according to their own learning progress, and educational tools that allow students to study anytime and anywhere were realized as PSE. "

He mentioned that PSE, which started in the "research field," can be applied to the "education field," and that it has already been realized in some cases.

As Prof.Tago pointed out, "research" and "education" have progressed as two wheels in the 
subsequent PSE workshops, study groups, and section meetings at academic conferences.

The main topic of this paper is "education," but before that, I would like to touch on "research" for a moment.

\section{BACKGROUND IN TWO FIELDS}

\subsection{Research fields}

Computational science, which uses computers for high-speed computation in various scientific pursuits, has evolved not only with improvements in algorithms but also with improvements in the computing power of computers themselves. First of all, vector computation has dramatically increased the computing power of individual computers, and then parallel computation has been added, so that the overall computing power of computers is still increasing year by year.

This trend is no exception in my field of expertise, QCD (Quantum Chromodynamics). However, parallel computing, which efficiently distributes the entire computation across multiple processors, has required many barriers to be overcome, especially for beginners.

In the late $1990 \mathrm{~s}$, in addition to the standard MPI, there were also proprietary libraries such as Paragon and NWT/VPP, and users had to rewrite the code each time they used them.

The author created QCDMPI[2] which can be applied to QCD calculations on parallel computers such as NWT and MPI as well as standalone computers with a single code, and released it as PDS(P

translation project of provided a Japanese 1 who do not have an proud to have played
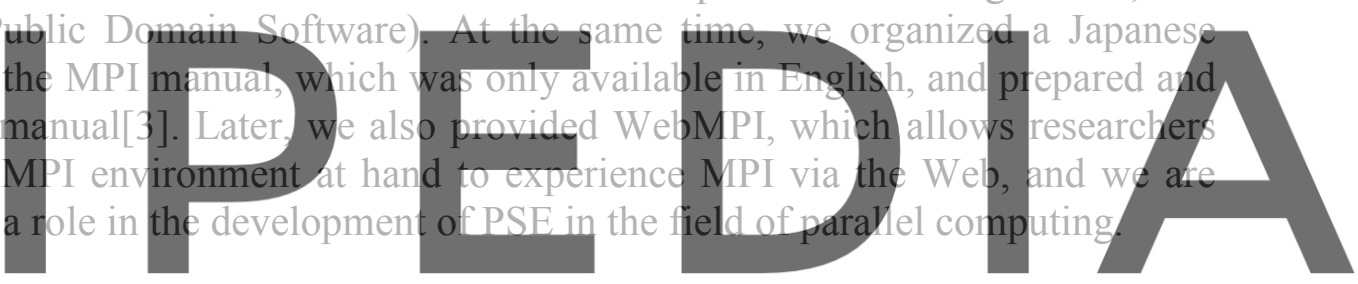

\subsection{Educational fields}

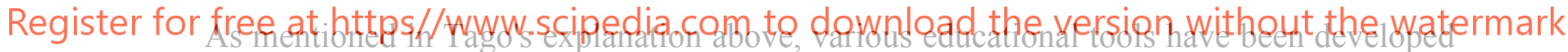
as PSE. What is the major difference between "research" and "education"? In my opinion, it is motivation. In the worid, there is what is commoniy calied the 2:6:2 rule. Of the total number of employees, $20 \%$ are self-motivated and produce results. It is often used to say that the next $60 \%$ are normal and the remaining $20 \%$ do not move easily.

I believe that this rule holds true in the field of education as well. $20 \%$ of learners do their own learning and produce results. $60 \%$ of them can learn reasonably well with the right kind of education. The remaining $20 \%$ have a problem with their attitude toward learning. In the case of universities, there are students who pay high tuition fees but do not show up for class.

Well, in many cases, it is not the students themselves who actually pay the tuition, but their parents or guardians.

Even for $60 \%$ of the learners, there is a phenomenon where the motivation they had in the early stages of learning declines as they progress. This is a case where there is no "maintenance of motivation" as it is commonly called. In some cases, the student hits a wall somewhere and becomes frustrated before he or she can overcome it. We believe that "educational PSE" is the key word to remove this barrier to learning.

With this in mind, I would like to briefly explain the "educational PSE" that I have been 
working on, and then refer to "programming education," which I am currently working on, and "information moral education," which I am still working on but which is expected to become more important in the future.

\subsubsection{Typing}

Typing is essential for any PC work, not to mention programming. Many people are still striving to achieve "touch typing," which is typing the keys without looking at the keyboard. This is evident from the large number of books available by searching for "typing books". Also, if you search for "typing sites," you can find many sites for self-study.

The author developed "Typing by ear" software [4] and used it in the classroom. As shown in Figure 1, students who were originally slow typists were able to increase their typing ability several times as a result of using this software, demonstrating its effectiveness for beginners.

At the same time, a typing contest is held once a year on campus to keep students motivated. Many students strive to win prizes and the envy of their friends. This year marks the 20th anniversary of the contest.[5]
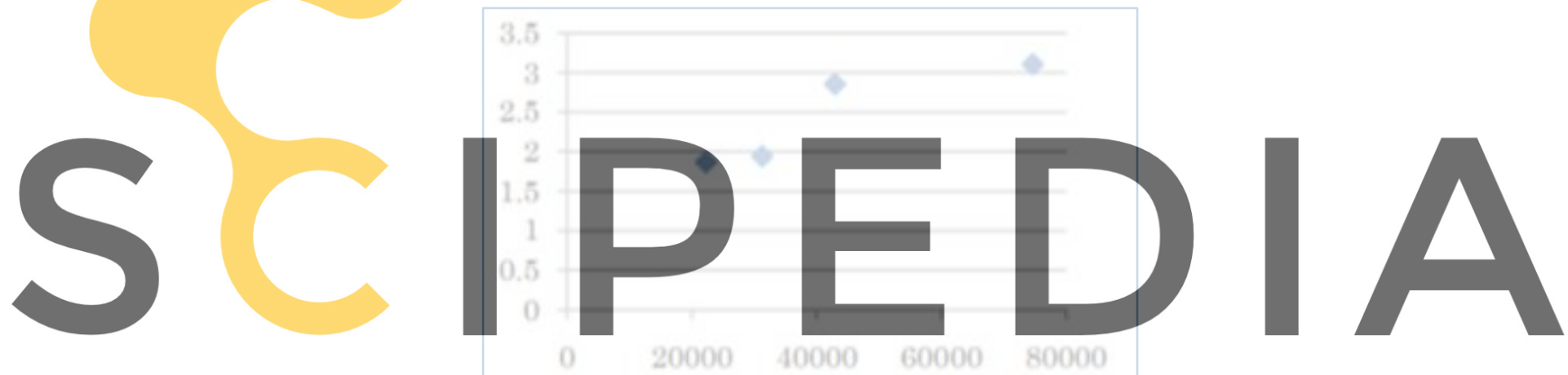

\section{Register for free at https//www.scipedia.com to download the version without the watermark}

Figure 1: Percent improvement in typing performance learned by ear (vertical axis). The horizontal axis is the time taken to type as measured before learning, with slower learners on the right.

\subsection{2 e-learning TIES, CHiLO}

As mentioned in the "2:6:2" rule above, e-learning is thought to be effective in removing one of the barriers during the learning process. Anybody can enjoy the education they need, anytime and anywhere, on the Internet. Currently, the MOOC environment is well known.

For more than 20 years, I have been providing self-study materials using TIES[6], which was originally developed at Tezukayama University and later became widely used.

With e-learning, if you have the motivation, you can progress rapidly. Nevertheless, learners encounter a variety of barriers. One of the main reasons is the difficulty in maintaining motivation.

The authors decided to use CHiLO[7] following TIES to divide learning units into small units called "nano-lectures" so that students can work on learning in their spare time, and to give unprecedented motivation to learners by giving them a "badge" for accomplishing each unit. 
Recently, the term "micro-learning" has become popular to describe the attitude of working in the gap, but is it just me who thinks that "nano" is more cutting-edge than "micro" because it is smaller?

\subsubsection{Computer Networking}

The Internet is now an indispensable part of society's infrastructure. One of the students who was studying network technology said, "I can't keep up my motivation. So, in 2008, we launched the Network Skills Competition (NSC[8]), a semi-annual competition held at universities across Japan. In some cases, we were able to match the participating students with the companies that came to see the competition, and we believe that we played a role in this.

Later, the "ICT Troubleshooting Contest "[9] with a similar concept to the NSC was also started. This contest has continued to be held every six months until now.

\section{PROGRAMMING EDUCATION}

The situation for learners of programming is the same as that of typing and e-learning in general. There are many books on programming, and you can find as many learning sites as you want on the Internet.

For the $20 \%$ of learners who are highly motivated by the $2: 6: 2$ rule, this is a great thing. However, for the remaining $80 \%$ of learners, I wondered if the environment was really easy to understand, and came to the conclusion that it would be a good idea to create a "problem-

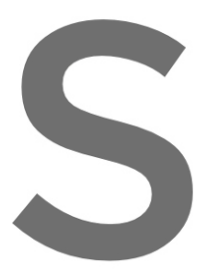
solving" programming

$3.1 \mathrm{C} 0$ We decided to start with the

(1) Output

(2) Variables

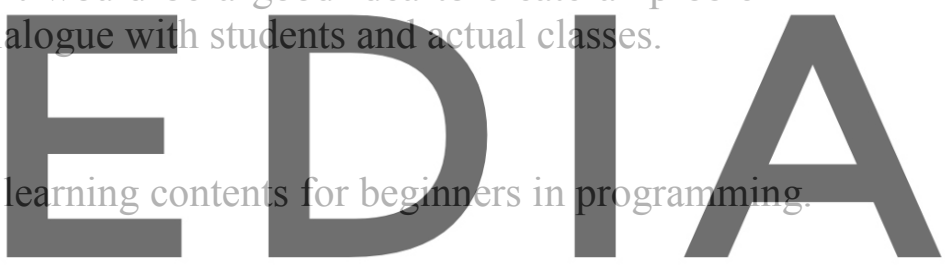

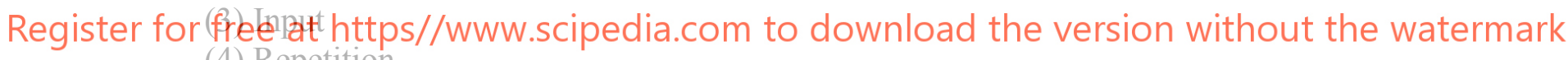
(4) Repetition

(5) Conditional branching

(6) Calculation of maximum value

\subsection{Programming Languages}

As programming languages, we chose "scratch," which is easy for beginners, "C++," which represents the standard $\mathrm{C}$ language, and "Python," which is very popular these days and has newly entered the language of the Information Processing Test.

By learning the same process in different languages, we believe that students will be able to deepen their understanding of programming from different angles.

\subsection{Questions as Problems}

The problem-solving style here refers to the style of presenting a problem from the beginning and coming up with a solution to it, rather than a lengthy explanation followed by a task as in a typical textbook. If you can clear this, then you can use existing learning sites to hone your skills. 
In response to the learning content in 3.1, we have prepared the following assignments, where you can actually do the programming, and if the results are correct, you can proceed to the next step, if not, you can start over, and if you want to get hints or correct answers, you can look at the examples of correct answers.

Example problems

(1) Output

Output "Hello".

(2) Variable

Assign the integer 1 to variable "a" and output the value of variable "a".

Assign the letter "hioki" to variable "a", and output the value of variable "a".

(3) Input

Assign the integer input from the keyboard to variable "a", and output the value of "a".

Assign the integer entered from the keyboard to the variable "a", and output the value of "a"+1.

(4) Repeat

Output "Hello" five times.

Repeat the following five times.

Substitute the integer input from the keyboard into the variable "a", and output the value of "a".

(5) Conditional branching

Substitute the integer input from the keyboard into the variable "a",
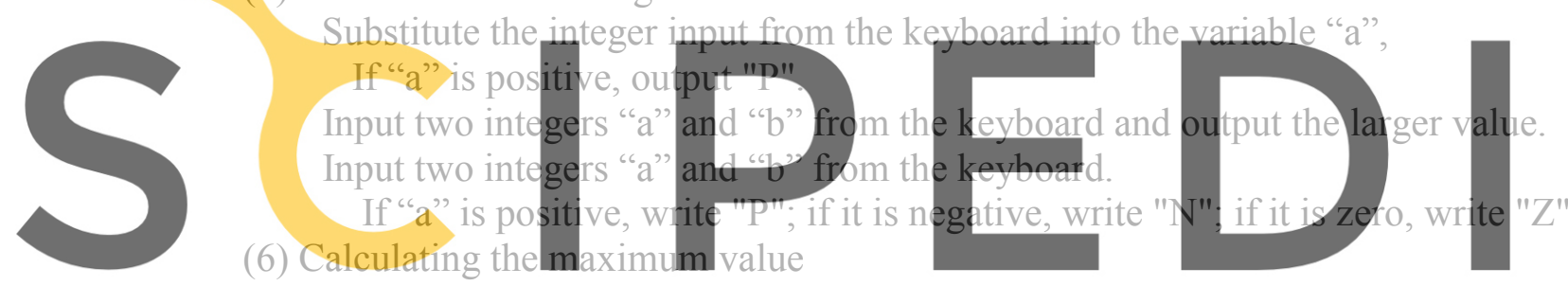

(6) Calculating the maximum value

Input 10 integers from the keyboard in order

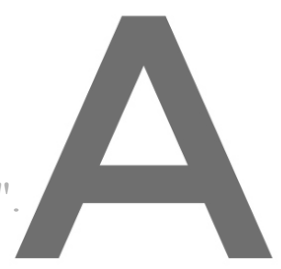

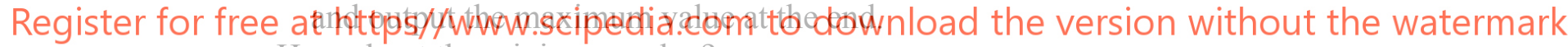

How about the minimum value?

\subsection{Evaluation in University Class}

We used this learning method (part of it) in various places, including open lectures, high school and university cooperative classes, and actual university classes. In the university class with the largest number of students and the longest class hours, I compared the pass rate on the final exam with other classes I had taken in the past in order to see the learning outcomes.

Unfortunately, there were no classes with the same content in the past, so Figure 2 shows a comparison with a class on "Network", which is the same in terms of IT.

In conclusion, there was no clear difference. As for myself, I feel remorseful that I caused $20 \%$ of the students to drop out. I realized once again that it is not easy to maintain the motivation of learners.

I will continue to take these results seriously and work hard to develop PSE in education. 


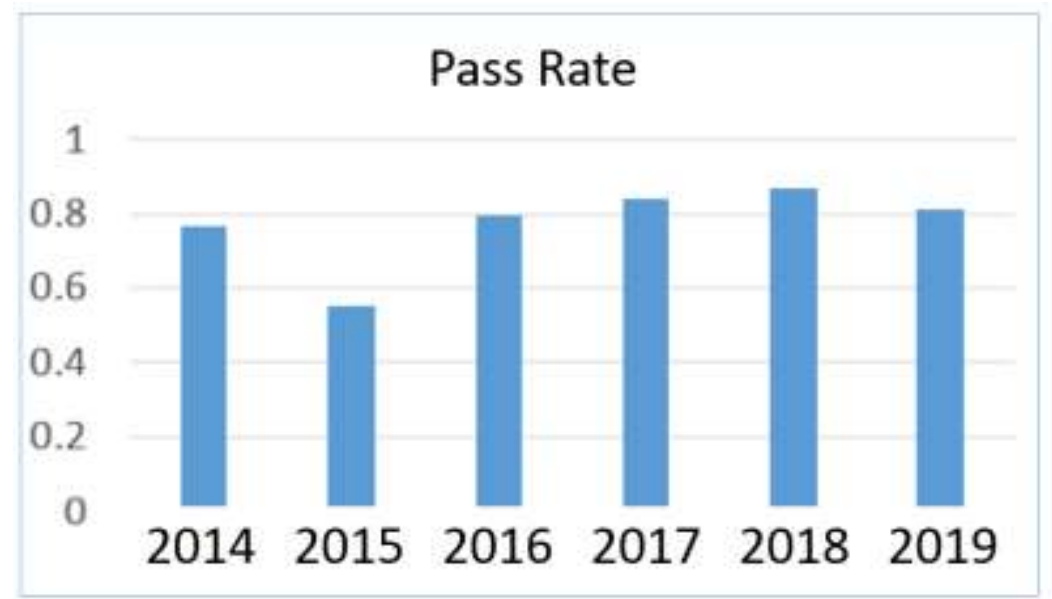

Figure 2: Pass rate per year (number of successful applicants / number of students)

\section{SUMMARY AND INFORMATION ETHICS EDUCATION}

Nowadays, almost all high school students have a smartphone and use it daily. The possibilities for education are endless with mobile devices that can connect to the Internet anytime, anywhere. Recently, however, the negative side of mobile devices has become a serious problem.

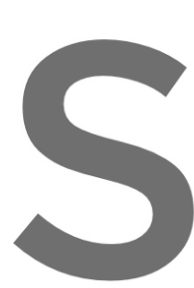

It is estimated that in one out of every two pe and evildoers, and there direct access to young people.

For this reason, it is necessary to take measures such as harmful information, which is required by la
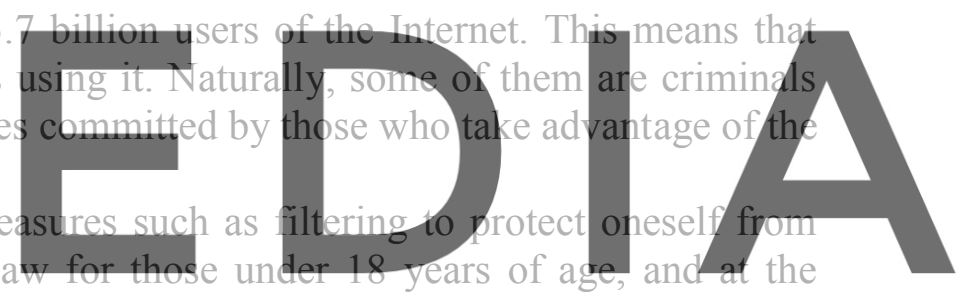
same time, "information morality education" for young people who may become victims must Register for freeoatdhttps//www.scipedia.com to download the version without the watermark

Now that we are facing these issues, we as PSE researchers have been searching for ways to help. If you have any good wisdom, I would be very grateful for it.

\section{REFERENCES}

[1] Yoshio Tago, "Pse Short Story", 13 ${ }^{\text {th }}$ PSE Workshop 2010.

[2] QCDMPI, http://insam.sci.hiroshima-u.ac.jp/QCDMPI/,Shinji Hioki, Parallel Computing 22 (1996) 1335.

[3] MPI Japanese Translation version, http://www2.kobe-u.ac.jp/ lerl2/mpi_j.pdf.

[4] Shinji Hioki,"Typing by Ear”, JUCE jornal2010, http://www.juce.jp/archives/taikai_2010/e-09.pdf

[5] Tezukayama University Typing Contest, http://webmpi2.sakura.ne.jp/roman/

[6] TIES, https://ja.wikipedia.org/wiki/TIES

[7] CHiLO, https://www.cccties.org/activities/all-about-chilo/

[8] Network Skills Competition: NSC, (sorry for Japanese) https://ja.wikipedia.org/wiki/\%E3\%83\%8D\%E3\%83\%83\%E3\%83\%88\%E3\%83\%AF\%E3\%83\%BC\%E3 \%82\%AF\%E3\%83\%BB\%E3\%82\%B9\%E3\%82\%AD\%E3\%83\%AB\%E3\%82\%BA\%E3\%83\%BB\%E3\% 82\%B3\%Е3\%83\%B3\%E3\%83\%9A\%E3\%83\%86\%Е3\%82\%A3\%Е3\%82\%B7\%Е3\%83\%A7\%Е3\%83\% B3

[9] ICT Troubleshooting Contest, https://icttoracon.net/ 